\title{
Choosing attentional control settings in a dynamically changing environment
}

\author{
Jessica L. Irons ${ }^{1}$ • Andrew B. Leber ${ }^{1}$
}

Published online: 17 May 2016

(C) The Psychonomic Society, Inc. 2016

\begin{abstract}
Goal-directed attentional control supports efficient visual search by prioritizing relevant stimuli in the environment. Previous research has shown that goal-directed control can be configured in many ways, and often multiple control settings can be used to achieve the same goal. However, little is known about how control settings are selected. We explored the extent to which the configuration of goal-directed control is driven by performance maximization (optimally configuring settings to maximize speed and accuracy) and effort minimization (selecting the least effortful settings). We used a new paradigm, adaptive choice visual search, which allows participants to choose one of two available targets (a red or a blue square) on each trial. Distractor colors vary predictively across trials, such that the optimal target switches back and forth throughout the experiment. Results $(N=43)$ show that participants chose the optimal target most often, updating to the new target when the environment changed, supporting performance maximization. However, individuals were sluggish to update to the optimal color, consistent with effort minimization. Additionally, we found a surprisingly high rate of nonoptimal choices and switching between targets, which could not be explained by either factor. Analysis of participants' self-reported search strategy revealed substantial individual differences in the control strategies used. In sum, the adaptive choice visual search enables a fresh approach to studying goal-directed control. The results contribute new
\end{abstract}

Jessica L. Irons irons.39@osu.edu

Andrew B. Leber leber.30@osu.edu

1 Department of Psychology, The Ohio State University, 225 Psychology Building, 1835 Neil Avenue, Columbus, OH 43210, USA evidence that control is partly determined by both performance maximization and effort minimization, as well as at least one additional factor, which we speculate to include novelty seeking.

Keywords Cognitive and attentional control · Visual search . Attention and executive control

One of the major pursuits in cognition research has been to understand the factors that control attention (Egeth \& Yantis, 1997; Yantis, 1998). Current research distinguishes between three broad sources of control: stimulus-driven, goal-directed and experience-driven control. Stimulus-driven control prioritizes visual information based on low-level salience, such as local feature discontinuities, transience, and brightness (Bergen \& Julesz, 1983; Donderi \& Zelnicker, 1969; Itti, Koch \& Niebur, 1998; Nothdurft, 1993; Treisman \& Gelade, 1980, Yantis \& Jonides, 1984; Yantis \& Jonides, 1990). In goal-directed control, task-relevant features and properties are prioritized in service of a top-down goal (Folk, Remington \& Johnston, 1992; Green \& Anderson, 1956; Smallman \& Boynton, 1990; Smith, 1962; Treisman \& Sato, 1990; Wolfe et al., 1990). Experience-driven control, or selection history, covers ways in which guidance is driven by an individual's recent experience or learning, such as recent strategy usage (Leber \& Egeth, 2006a, 2006b, Leber, Kawahara \& Gabari, 2009; Vatterott \& Vecera 2012), priming (Maljkovic \& Nakayama, 1994), and reward learning (Anderson, Laurent \& Yantis, 2011; Della Libera \& Chelazzi, 2006; Navalpakkam, Koch, Rangel \& Perona, 2010).

Substantial gains have been made in understanding these sources of control. For stimulus-driven and experience-driven control in particular, careful and exhaustive manipulation of stimulus properties and learning/priming procedures, 
respectively, have enabled a detailed understanding of the conditions under which these forms of control operate. Understanding goal-directed control, however, has proven more intractable. This is because there is no way to precisely manipulate an observer's goal-directed state; researchers can only instruct participants to use a certain strategy, e.g., "please search for the square" or "please ignore the red distractor," and hope that participants comply. This approach neglects that observers often have multiple control settings available (Bacon \& Egeth, 1994), and they may not always use the optimal strategy or the one that the experimenter wishes to study. One solution has been to constrain the task to such a degree that the number of available search strategies is restricted. Doing so, however, sacrifices ecological validity. Realworld search tasks are highly unconstrained, and observers are provided with no specific instructions about how they should search.

To develop a full understanding of goal-directed control, we need to understand how it is configured and which factors motivate individuals to adopt one particular setting over another. This paper represents a step forward in this pursuit. We start with a basic review of goal-directed control and discuss theories and findings from related literatures. We then introduce a new paradigm that was inspired by this survey of the literature, which we term the adaptive choice visual search. Finally, we report initial results from this paradigm, which begin to advance our understanding of goal-directed control.

\section{Goal-directed attentional control}

Goal-directed control has been the subject of considerable interest for decades. Early work showed that in visual search tasks, attention could be voluntarily directed towards specific spatial locations (Sperling, 1960; Eriksen \& Hoffman, 1972) or towards items with a particular feature (Posner, Nissen \& Ogden, 1978; Smith, 1962; von Wright, 1970). Green and Anderson (1956), for example, found that when participants searched through multicolored displays, foreknowledge of the target color reduced response times, and varying the number of nontarget colored items had little effect on search time. Later models of visual search proposed the concept of feature maps, which are representations of the spatial locations of various feature values in the environment (Treisman, 1988; Treisman \& Gelade, 1980; Wolfe, 1994; 2007; Wolfe, Cave \& Franzel, 1989). By increasing the activation of a specific feature value (e.g., red), items matching this feature will be prioritized for visual processing. This and other work helped formed the basis for the concept of an attentional control setting or attentional template: a representation of taskrelevant feature or properties that governs the prioritization of visual stimuli in the environment (Folk et al., 1992;
Duncan \& Humphreys, 1989). Attentional control settings provide sizable search benefits, by reducing the number of stimuli that require thorough processing and by preventing attentional capture by salient but irrelevant stimuli (Folk et al., 1992).

Subsequent research has uncovered much information about the types of attentional control settings that can be established. Collectively, these studies show that attentional control settings can be flexibly tuned to a range of different properties. At one level, attentional control settings can be quite broad. In "singleton detection mode," attention is biased towards any unique items, or "oddballs," in the environment (Bacon \& Egeth, 1994; Pashler, 1988). Attention also can be set more narrowly for transient events, such as the onset or offset of an object (Atchley, Kramer \& Hillstrom, 2000; Folk \& Remington, 1998) or the onset of movement (Folk, Remington \& Wright, 1994), and to static features, such as color, orientation, size, and shape (Ansorge \& Heumann, 2003; Ansorge \& Horstmann, 2007; Ansorge, Hortsmann, \& Carbone, 2005; Folk \& Anderson, 2010; Folk, Leber \& Egeth, 2002; 2008; Folk \& Remington, 1998; Lamy, Leber \& Egeth, 2004; Becker, 2008; Wolfe \& Horowitz, 2004). It also has been argued that attention can be tuned to a directional relationship between targets and distractors in feature space (e.g., prioritizing the "redder" items in the display; Becker, 2010; Becker, Folk, \& Remington, 2013). Recent work suggests that attention can be set for multiple features concurrently (Adamo, Wozny, Pratt \& Ferber, 2010; Barrett \& Zobay, 2014; Beck, Hollingworth \& Luck, 2012; Irons, Folk \& Remington, 2012; Kristjánsson, Jóhannesson \& Thornton, 2014; Moore \& Weissman, 2010, 2011; Roper \& Vecera, 2012) and possibly even more abstract semantic relations or category membership (Ariga \& Yokosawa, 2008; Barnard, Scott, Taylor, May \& Knightley, 2004; Leblanc \& Jolicoeur, 2007; Wyble, Bowman \& Potter, 2009; Wyble, Folk \& Potter, 2013). Attentional control settings can be updated relatively flexibly and can switch between features in response to new task instructions with little carryover and a relatively short delay (Lien, Ruthruff \& Johnston, 2010; Lien, Ruthruff \& Naylor, 2014; Vickery, King \& Jiang, 2005).

\section{Configuring attention control}

Despite the wealth of research on goal-directed control, we still know very little about how attentional control settings are selected. What factors influence how goal-directed control is configured? One assumption is that goal-directed control is configured optimally to maximize performance, that is, achieve the search goal with the highest speed, accuracy and/or reward. This performance maximization account can be derived from the principle of maximum utility, which holds that individuals will choose the option that has the greatest 
overall benefit to cost ratio (Simon, 1959; von Neumann \& Morgenstern, 1953). Performance maximization in attentional control implies that an individual should always choose the optimal attentional control setting. This can be defined as a setting for the feature(s) or properties(s) that best separate the target from its environment. For example, when searching for a teacher among a group of children, setting up a search based on his/her size will lead to efficient performance. Performance maximization requires regular monitoring of the environment and updating of the attentional control settings to suit each new environment. For instance, when the teacher is now surrounded by other teachers, a size-based search will no longer be useful, and searching based on his/her distinctive sweater would be a more successful strategy. Optimal configuration also depends on the limitations of the attentional and working memory system; for instance, the ideal attentional set for a capacity-unlimited system may be composed of the precise configuration of all features of the sought after target (e.g., tall, red sweater, brown hair, etc.), but many studies show that humans are unable to guide attention efficiently to a conjunction of even two features (Treisman \& Gelade, 1980).

Many aspects of visual search behavior have been shown to help maximize performance, such as directing fixations to locations that enhance information gathering (Najemnik \& Geisler, 2005), strategically increasing the gain of neurons preferring features slightly different to the target to maximize target-distractor discrimination (Navalpakkam \& Itti, 2007; Scolari \& Serences. 2009), and adjusting time spent searching a display based on the rate of target yield (Cain, Vul, Clark \& Mitroff, 2012; Wolfe, 2013). In most goal-directed control studies, where task instructions specify the optimal search feature, attentional control settings do show at least some tendency toward optimal selection (e.g., when told to search for a red target, participants will show an overall preference to prioritize red items but not green or blue; Smallman \& Boynton, 1990; Wolfe, Yu, Stewart, Shorter, Friedman-Hill, \& Cave, 1990). Moreover, when instructions are less specific and search thus less constrained, there is some evidence that participants optimize performance. For example, in the subset search task, participants search for a conjunction target amongst two types of distractors (e.g., green X amongst green Os and red Xs). When the ratio of the distractors is manipulated, resulting in more of one type of distractors than the other, observers are more likely to search through the set of distractors with the fewest items (Egeth, Virzi, \& Garbart, 1984; Shen, Reingold, \& Pomplun, 2000; Sobel \& Cave, 2002). While this may be partly driven by salience (Sobel \& Cave, 2002), the effect is present even when salience is controlled for (Kaptein, Theeuwes, \& Van der Heijden, 1995) and is amenable to instruction (Bacon \& Egeth, 1997), suggesting an important role for goal-directed control.

Conversely, a number of cases from the visual search literature do not fit within a performance maximization framework. A seminal study by Bacon and Egeth (1994) showed that individuals often choose suboptimal attentional sets. In their study, participants searched for a circle target that was either a shape singleton (i.e., one circle amongst diamonds) or not (i.e., one of multiple circles amongst diamonds). An additional, taskirrelevant color singleton distractor captured attention only in singleton search, which the authors took as evidence that participants used singleton detection mode when the target was a singleton and feature search mode when it was not a singleton. A surprising implication of these results is that the participants using singleton detection had chosen the option that led to the most distraction, despite the fact that they were clearly capable of using the more effective feature search mode (see also Folk \& Anderson, 2010; Irons et al., 2012; Kawahara, 2010; Leber \& Egeth, 2006a, 2006b; Leber et al., 2009; Proulx, 2011). Along similar lines, recent work by Gibson and colleagues (Davis \& Gibson, 2012; Pauszek \& Gibson, 2016) challenges the assumption that observers always take advantage of predictive information to voluntarily guide attention. They found that symbolic cues indicating target location were often ignored, with participants preferring to search unaided than to interpret the cue.

Why would people sometimes use suboptimal settings? Bacon and Egeth (1994) speculated that it came down to cognitive effort: feature-search mode may require more effort than singleton detection mode to maintain. Humans generally avoid effort expenditure when possible, even at the expense of performance (Muraven \& Baumeister, 2000). For example, eye movement studies have shown observers to prefer suboptimal, but less effortful, saccadic planning strategies (Araujo, Kowler \& Pavel, 2001; Zelinsky, 1996). This trade-off between effort and performance has played a key role in models of decision-making (Bettmann, Johnson, \& Payne, 1990; Hull, 1943; Johnson \& Payne, 1985, Russo \& Dosher, 1983) and, more recently, cognitive control (Botvinick \& Braver, 2015; Botvinick \& Rosen, 2009; Walton, Bannerman, Alterescu, \& Rushworth 2003). These latter studies suggest that before exerting control, the cognitive control system weighs the effort required against the potential rewards, and control is only adjusted if the expected reward outweighs the cost of effort. In Bacon and Egeth's study, the benefits of using feature search mode would have been relatively minor (20$30 \mathrm{~ms}$ faster for each trial in which distraction is avoided, summing cumulatively to a mere few seconds over the hundreds of trials in the experiment; see Egeth, Leonard \& Leber, 2010), but the increase in effort may have been substantial.

While there are arguably many different sources of cognitive effort, we propose three specific ways in which minimizing effort may impair performance maximization. First, optimal attention control involves proactive mechanisms to maintain task goals actively and monitor the environment for changes (Braver, 2012; Braver, Gray \& Burgess, 2007). Sustaining proactive control over time is effortful (Braver et al., 2007; Chatham, Frank \& Munakata, 2009; Locke \& Braver, 2008). To minimize effort, observers may revert to reactive control, which is triggered only after stimuli have 
been presented and is generally less effective than proactive control (Braver, 2012). Second, observers may avoid updating old attentional control settings to new, more effective settings. Switching between cognitive tasks, e.g., judging a digit's magnitude or parity, is resource demanding, and previous studies have shown that observers tend to avoid switching (Kool et al., 2010; Arrington \& Logan, 2004). Finally, optimal performance requires observers to continually monitor both their performance and the task environment, judging the effectiveness of the current strategy relative to the task demands (Cain et al., 2012; O'Leary \& Sloutsky, 2016; Wolfe, 2013). This process engages conflict-monitoring mechanisms, including the anterior cingulate cortex (Botvinick, Braver, Barch, Carter, \& Cohen, 2001). Because of the continued engagement of cortical regions in conflict monitoring, it is inherently resource-demanding, a notion supported by the finding that conflict monitoring is impaired during cognitive fatigue (Lorist, Boksem, \& Ridderinkhof, 2005).

Together, these three forms of effort minimization - reactive control, switching avoidance, and reduced performance monitoring - all emphasize avoiding effort in the present moment. Paradoxically, because of the inefficiencies they produce in behavior, these forms of effort minimization may result in greater expenditure of another kind of effort, or resource expenditure, in the long-term. For instance, using nonoptimal attentional control settings could yield substantially slower, less efficient visual search latencies. To be clear, when we refer to cognitive effort in this paper, we specifically mean the three momentary forms of effort we have described in the context of previous theoretical and empirical work.

\section{The present study}

The purpose of the present study was to explore how goal-directed control is configured in an unconstrained environment and the extent to which it is configured in an optimal manner. In particular, we sought to determine the degree to which individuals maximize performance versus minimize effort. To this end, we developed the adaptive choice visual search. The task takes advantage of subset search, where individuals use goal-directed control to search through a particular subset of distractors for a specific target (Green \& Anderson, 1956; Egeth et al., 1984). Our task used a large search display of approximately 50 small and large squares, each appearing in 1 of 4 possible colors. In addition, we added a choice component to the search process, by allowing participants to choose which target they would search for on each trial. This approach is analogous to a method in the task-switching literature that has examined the underlying control process associated with voluntary choices (Arrington \& Logan, 2004). In our task, two targets, a small blue square and a small red square, were presented on every trial, and participants were instructed to respond to one of these (see Fig. 1 for a sample search display). Participants were

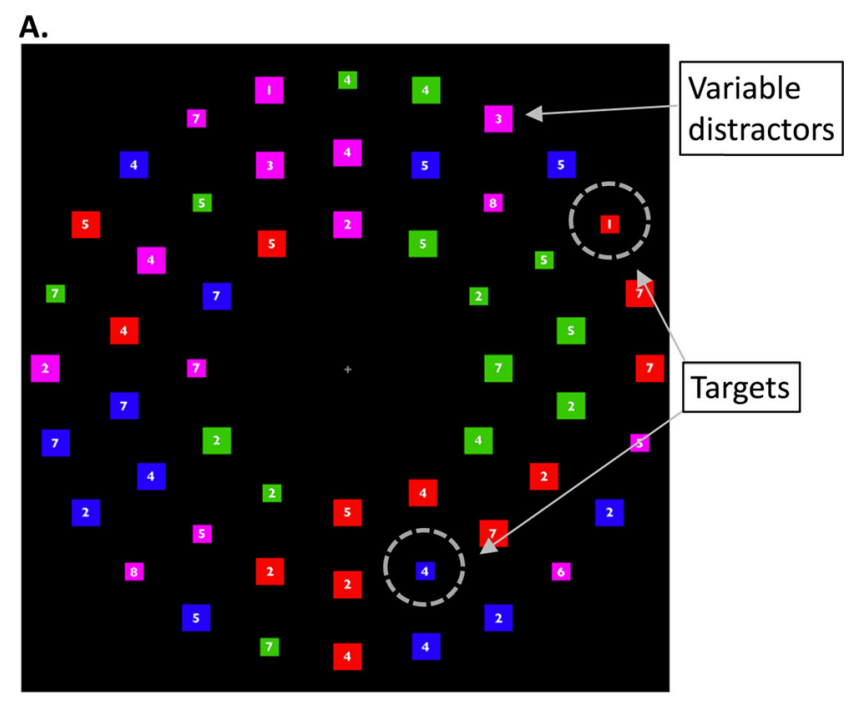

B. Variable Distractor color (24-trial cycle) Ved Red Transition $\begin{gathered}\text { Blue } \\ \text { Plateau }\end{gathered}$ Transition
Plateau

Fig. 1 a Example search display with variable distractors colored magenta (transition middle color). Targets (small red and small blue square with digit between 1 and 4) are circled. b Progression of the variable distractors colors across a cycle of 24 trials

free to choose either target on each trial, without any restrictions on how frequently they chose either one. The two targets were associated with different manual responses, allowing us to measure participants' choices on every trial. We also used eye-tracking to provide confirmation of the chosen target.

Additionally, to explore how well individuals update their attentional control settings - and if they do so optimally - we manipulated the search environment over the course of the experiment. The display was comprised of four sets of distractors: red, blue, green, and "variable" distractors. The color of the variable distractors changed discretely from trial to trial, oscillating between red and blue in color space (Fig. 1b). Specifically, the distractors were red for three trials (the red plateau). Then, over the next nine trials, they changed color in discrete steps from pinkish-red to magenta to purplishblue. They were then blue for three trials (blue plateau), followed by a second 9-trial transition from blue to red. The purpose of the variable distractor was to manipulate the relative efficiency of searching for either the blue or the red target. On the red plateau, the total number of red distractors in the display was essentially doubled. Thus, searching for blue would be the most efficient strategy. On the blue plateau, the red target would now be more efficient. As the variable distractors transitioned between the two colors, we predicted that the efficiency with which participants searched through each distractor set would vary as a function of the similarity between the target and the variable distractors (Anderson \& Folk, 2010; Ansorge \& 
Heumann, 2003; Duncan \& Humphreys, 1989). Thus, the optimal target changes in the middle of each color transition.

We predicted that if participants maximize performance on this task, they should always choose the optimal target. Because our task provides a continuously changing environment, knowing which target is optimal requires continuous performance monitoring. Specifically, on the red plateau, participants should search for the blue target. Likewise, on the blue plateau, they should search for the red target. During the transition, participants should switch their chosen target at the midpoint. In contrast, if participants minimize effort, they may fail to monitor changes in the environment or show a reluctance to update their control settings in response to these environmental changes. Thus, they might switch their chosen target color well after the midpoint of the transition, or they could avoid switching entirely, sticking with a single color for an extended period of time. To examine the extent to which participants maximized performance, we looked at two main dependent measures: 1) proportion of each target chosen on the plateau and at each point in the transition, and 2) the frequency with which participants switched between the two targets.

To gain baseline performance measures, we also ran two control visual search tasks. The Instructed Task was identical to the adaptive choice task, except that participants were instructed to search for one specific target for a full block of trials. This enabled us to measure response times to the two targets at each position in the run and to calculate the cost of searching for the less optimal target. In the Cued Switching Task, participants were cued to search for either the red or the blue target on each trial. We compared response time on switch trials (trials in which the target was different from the target on the previous trial) and repeat trials (trials in which the target was the same color as the target on the previous trial). This enabled us to gain a measure of the cost of switching attentional control settings within these search displays.

In addition to group level performance, we explored differences in behavior across individuals. Previous studies of cognitive task performance have shown marked differences in observers' choice of search strategy (Boot, Becic, \& Kramer, 2009; Boot, Kramer, Becic, Wiegmann \& Kubose, 2006) and the extent to which they maximize performance or minimize effort (Kool et al., 2010; Kool, McGuire, Wang, \& Botvinick, 2013). We took a number of approaches to exploring individual differences. First, at the end of the adaptive choice task, we asked participants to self-report their strategy for choosing tasks as well as their awareness of the variable distractor color change. We examined the extent to which performance varied as a function of individuals' self-report. Second, we looked at whether an individual's performance on the control visual search tasks predicted performance on the adaptive choice task. Finally, we measured participants' visual working memory capacity and impulsivity, both of which have been correlated with attentional control (Fukuda \& Vogel, 2011; Kane, Bleckley, Conway \& Engle, 2001; Sarter \& Paolone, 2011).

\section{Method}

\section{Participants}

Forty-nine participants completed the first session of the study. Of these, five did not return for the second session. The remaining 44 participants ( 17 males and 26 females) ranged in age from 18 to 40 years (mean $[\mathrm{M}]=22.5$, standard deviation $[\mathrm{SD}]=4.0$ ). All reported normal or corrected-tonormal visual acuity and normal color vision. Participants completed two sessions of 1-1.5 hours each, and received $\$ 10$ per hour (\$30 total) for participating. All experimental methods were approved by The Ohio State University Institutional Review Board, and all participants provided informed written consent.

\section{General procedure and apparatus}

All participants completed the tasks in the following order: Session 1 - Instructed task, Cued Switching task; Session 2 - Adaptive Choice visual search, working memory capacity task, and Barratt Impulsiveness Scale. The experiment was conducted in a dimly lit, sound-attenuated testing room. Participants were positioned $56 \mathrm{~cm}$ from the computer monitor, with their head position with a chin rest. All experiments were run using the Psychophysics Toolbox (Brainard, 1997; Pelli, 1997) with Matlab (Mathworks, Natick, MA), on an Apple Mac Mini with a 24-inch monitor (resolution: $1920 \times$ 1080; refresh rate: $60 \mathrm{~Hz}$ ). Eye tracking was performed using an Eyelink 1000 desk-mounted eye tracker (SR Research, Mississauga, ON, Canada). Eye tracking was used for the three visual search tasks (adaptive choice, instructed, and cued switching tasks) but not for the visual working memory task.

\section{Adaptive choice visual search}

Although the adaptive choice task was presented in the second session, we describe it in detail first, as it was the main focus of the study. The instructed and cued switching tasks from Session 1 are described subsequently.

Stimuli The visual search display (Fig. 1) was composed of 54 colored squares arranged in three concentric rings around a grey central fixation cross (inner ring: $6.7^{\circ}$ from fixation; middle ring: $10.1^{\circ}$ from fixation; outer ring: $13.4^{\circ}$ from fixation). There were 12 items in the inner ring, 18 in the middle ring and 24 in the outer ring. The distance from the center of each item to the next along the ring was $3.6^{\circ}$. The squares were either small 
$\left(0.9^{\circ} \times 0.9^{\circ}\right)$ or large $\left(1.3^{\circ} \times 1.3^{\circ}\right)$. Each display contained two targets: a small red and a small blue target. There were four sets of distractors: red distractors (12 large red squares), blue distractors (12 large blue squares), green distractors (7 large and 7 small green squares), and "variable" distractors (7 large and 7 small squares). We report the CIE and RGB color values of all distractors in Table 1. The color of the variable distractors oscillated from red through magenta to blue, and back again, over the course of 24 trials. For the first three trials of the cycle, the distractors were red ("red plateau"). The color values then stepped in regular intervals across color space from pinkish-red to magenta, and then from magenta to purplish-blue ("transition"). The transition was nine trials long, with magenta at the center. This was followed by three trials with blue distractors ("blue plateau"), after which the colors transitioned from blue back to red. A run was defined as a single plateau plus the ensuing transition (12 trials total). The green items were always completely irrelevant to the task and acted as a baseline for measuring item fixations. Additionally, the green items were of roughly equal salience to the blue and red and items, which prevented target choice from being guided by stimulus-driven salience on the plateaus.

Each square contained a white digit between 1 and 8 , subtending $0.4^{\circ} \times 0.4^{\circ}$. The digits were small enough that they required gaze to be fixated in their vicinity to be identified. The targets (small red and small blue square) always contained a digit between 1 and 4 and were always different from each other to identify the chosen target. The small variable distractors always contained a digit between 5 and 8, ensuring that they would not be misreported as targets, particularly on the plateaus (when the variable distractors were red or blue). The digits inside the remaining items were each assigned randomly.

Procedure Instructions at the start of the task informed participants that two targets (small red and small blue square with digit between 1 and 4 ) would be presented on every trial, and

Table 1 RGB and CIE XYZ color values

\begin{tabular}{lllllrr}
\hline & \multicolumn{1}{c}{ RGB } & \multicolumn{5}{c}{ CIE XYZ } \\
\hline Red & 255 & 0 & 0 & 42.24 & 21.26 & 1.93 \\
Blue & 0 & 0 & 255 & 18.05 & 7.22 & 95.05 \\
Green & 0 & 200 & 0 & 20.65 & 41.31 & 6.89 \\
Variable distractors & 255 & 0 & 51 & 41.84 & 21.50 & 5.08 \\
$\quad$ (red-to-blue transition) & 255 & 0 & 102 & 43.64 & 22.22 & 14.56 \\
& 255 & 0 & 153 & 46.99 & 25.56 & 32.21 \\
& 255 & 0 & 204 & 52.15 & 25.62 & 59.32 \\
& 255 & 0 & 255 & 59.29 & 28.48 & 96.98 \\
& 204 & 0 & 255 & 4295 & 20.06 & 96.22 \\
& 153 & 0 & 255 & 31.19 & 13.99 & 95.67 \\
& 102 & 0 & 255 & 23.53 & 10.05 & 95.31 \\
& 51 & 0 & 255 & 19.42 & 7.92 & 95.11 \\
\hline
\end{tabular}

that they should respond to only one of these, by pressing a keyboard button that corresponded to the chosen target digit. Participants could respond with four fingers from one hand or two from each hand, but they were required to remain consistent for all three search tasks. Participants were free to switch between the two targets as frequently or infrequently as they liked. They were also told that on some trials there would be more red distractors than blue distractors, and they may find it easier to search for blue on these trials. On others, there would be more blue than red distractors, and they may find it easier to search for red. However, they should feel free to choose whichever target felt easiest to them at the time.

The task involved five blocks of 120 trials each (10 runs of the variable distractor), giving 600 trials total, plus 12 practice trials. The trials started at the beginning of either a red or blue plateau (counterbalanced across participants). Each trial began with the fixation cross for $1500 \mathrm{~ms}$. Participants needed to have their gaze on the fixation cross for the final $500 \mathrm{~ms}$ of this period; otherwise, the fixation cross remained onscreen until this requirement was satisfied. The search display was then presented and remained on-screen until a response was made. A short $(140 \mathrm{~ms})$ tone was played following errors. The positions of the targets and distractor items were randomized, and the target digits were pseudo randomized, with the restriction that the two targets never contained the same digits.

Eye positions were recorded every $2 \mathrm{~ms}$ for the duration of the trial and analyzed offline. A five-point calibration took place at the beginning of each block. Additionally, if the fixation control at the start of the trial was unable to detect a central fixation within 5 seconds, a short drift correction was performed. If the drift correction failed or was performed on at least eight trials within the same block, a recalibration was performed.

At the end of the Adaptive Choice task, participants completed a short self-report survey. The measure contained four open-ended questions, presented on the computer screen, one at a time. The first two questions were designed to gain an insight on the participants' subjective search strategies: 1) "On each trial, how did you decide which target to search for? Were there any particular factors that made you want to respond to one instead of the other?" and 2) "Did you switch between the two targets? If so, what made you decide to switch?" The next two questions addressed their awareness of the variable distractors: 3 ) "On some trials, there were more blue items in the display, and other times there were more red items. Did you get the impression that this change occurred abruptly, or gradually?" and 4) "Did you notice that some of the items in the display changed gradually from blue to purple to red, and then from red to purple to blue?"

\section{Instructed task}

In the instructed task, participants had to search for one specific target color on every trial for a full block. The search 
displays were identical to the adaptive choice task, except that only one of two possible targets (small red or blue square with digit 1-4 inside) was presented on each trial. The other small square was now assigned a distractor digit between 5 and 8 . Participants performed two blocks searching for the red target, interspersed with two blocks searching for blue. The starting target color was counterbalanced across participants. Additionally, half of the blocks started with the variable distractors at the red plateau, and half at the blue plateau, and this order was counterbalanced across participants. Each block had 120 trials, resulting in 480 trials total.

\section{Cued switching task}

In the cued switching task, participants were cued to search for a specific target on a trial-by-trial basis. The trial sequence began with the fixation cross for $500 \mathrm{~ms}$, followed by the word "RED" or "BLUE" in size 22, grey Gill Sans font in the center of the screen for $1000 \mathrm{~ms}$. The search display contained only one target (the cued target), and the variable distractors were held constant at magenta for the entire task. Participants completed two blocks of 120 trials, with each block containing equal numbers of red and blue targets. Trials were randomized with the restriction that the number of repeat trials (i.e., target is the same color as the target on the previous trial) and switch trials (i.e., target is a different color to the target on the previous trial) were almost equal (excluding the first trial, which could not be counted as either repeat or switch).

\section{Visual working memory capacity}

Working memory capacity was tested using the change detection task from Luck and Vogel (1997). Briefly, the stimuli consisted of displays of four or eight different color squares. The display was presented for $100 \mathrm{~ms}$, removed for $1000 \mathrm{~ms}$, and then presented a second time for $3000 \mathrm{~ms}$. On the second presentation, the display was either identical to the first presentation, or one of the squares had changed color. Participants indicated via keypress whether the squares were all the same color or whether one had changed. Working memory capacity $(\mathrm{k})$ was estimated using the standard formula from Cowan (2001).

\section{Barratt impulsiveness scale}

Trait impulsivity was measured using a pencil-and-paper version of the Barrett Impulsiveness Scale (BIS-11; Patton, Stanford \& Barratt, 1995). The BIS-11 contains 30 items requiring individuals to rate how frequently they engage in each behavior on a scale from 1 to 4. Examples include "I do things without thinking"; "I change hobbies"; and "I often have extraneous thoughts when thinking."

\section{Results and discussion}

Data from one participant whose accuracy on the Adaptive Choice task $(89.17 \%)$ was more than three SD below the group mean was removed from analyses. For the instructed tasks, data from an additional participant with accuracy $(83.27 \%)$ more than 3 SD below the mean also was removed. Incorrect trials and trials with response times (RTs) less than $300 \mathrm{~ms}$ or more than $3 \mathrm{SD}$ above the participant's mean were removed from analyses.

We first report the data from the two control visual search tasks (Instructed and Switch tasks). To preview, results from these two tasks confirm two assumptions we made when designing the adaptive choice task: 1) RT varies as a function of similarity between the target color and variable distractor color, and 2) switching between attentional sets incurs a response time cost.

\section{Instructed task}

RT data were analyzed at each of the 12 positions along the run: at each trial along plateau (P1-P3, collapsed across red and blue), and at each of the nine positions along transitions (T1-T9, where position T1 is the first trial of each transition and position T9 is the final trial before the next plateau). We collapsed red-to-blue transition and blue-to-red transitions across time, such that for half of the runs (red-to-blue transitions), T1 was almost red and T9 was almost blue, and for the other half (blue-to-red transitions), T1 was almost blue and T9 was almost red. This controlled for any asymmetries in color space (where the perceptual midpoint between red and blue is not exactly at the midpoint in color space) and enabled us to examine the point in time at which participants switched between targets. Data were collated separately for targets that were optimal on the plateau and at the start of the transition (start optimal, e.g., blue target on the red plateau and at the start of a red-to-blue transition), and targets that were optimal at the end of the transition (end optimal, e.g., red target at the end of a red-to-blue transition).

RT data are presented in Fig. 2. On plateau trials, participants were significantly faster to respond to targets when they did not match the variable distractors (i.e., red when the variable distractors were blue, and blue when they were red) than when they matched, a cost of $1687 \mathrm{~ms}$ averaged across the three plateau trials, $t(41)=18.43, p<0.001, d=7.46)$. On transitions, RTs varied as a function of similarity between the target and distractor color. RTs were faster for the Start Optimal color for the first four trials $(t \mathrm{~s}>4.28, p \mathrm{~s}<0.001)$ and then converged at positions T5 and T6 $(t \mathrm{~s}<1.02$, $p s>0.31)$. For the final three positions, the effect had reversed, as RTs were faster for the End Optimal color $(t \mathrm{~s}>3.81, p \mathrm{~s}<0.001)$. 


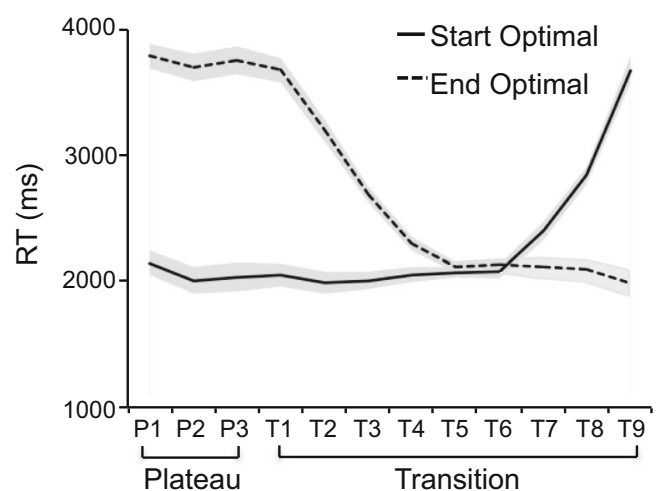

Fig. 2 Instructed task RTs at each position along a run. The Start Optimal target is the target that was most optimal on the plateau and at the beginning of the transition. The End Optimal target was most optimal at the end of transition. The $\mathrm{x}$-axis labels refer to each trial in a run, starting with the three plateau trials (averaged across red and blue trials) and the nine transitions trials (averaged over time across red-to-blue transitions and blue-to-red transitions). Error bands depict standard error of the mean differences between Start and End Optimal at each position in the run

\section{Cued switching task}

In the switch visual search task, performance was compared across repeat trials (target color was the same as the target on the previous trial) and switch trials (target color was different to the target on the previous trial). The results revealed a significant switch cost of $387 \mathrm{~ms}$, with slower RTs on switch trials $(M=2246 \mathrm{~ms})$ than repeat trials $(M=1858 \mathrm{~ms})$, $t(43)=6.81, p<0.001, d=1.41$.

\section{Adaptive choice task}

Response accuracy on the adaptive choice task was at ceiling $(M=98.33 \%, S D=1.31)$. To assess choice behavior, we looked at two main dependent variables: 1) target choice (proportion of trials in which participants selected each of the two possible targets) and 2) target switching (i.e., proportion of trials in which the chosen target color on trial $\mathrm{N}$ was different to the chosen target color on trial N-1).

Target Choices Choice data are plotted in Fig. 3. Data are plotted at each of the 12 positions in a run, and separately for the Start Optimal and End Optimal target. As with the Instructed task, red-to-blue and blue-to-red transitions were collapsed to control for any asymmetries across color space in the two transitions.

Beginning with the plateaus, participants showed a clear tendency to search for the start optimal target $(t(42)=3.84$, $p<0.001, d=1.19$, averaged across the three plateau trials). Across the transition, target choices changed as a function of similarity to the variable distractors, as demonstrated by a significant interaction between target choice and position in transition, $F(8,336)=14.03, p<0.001, \eta_{\mathrm{p}}^{2}=0.25$. These
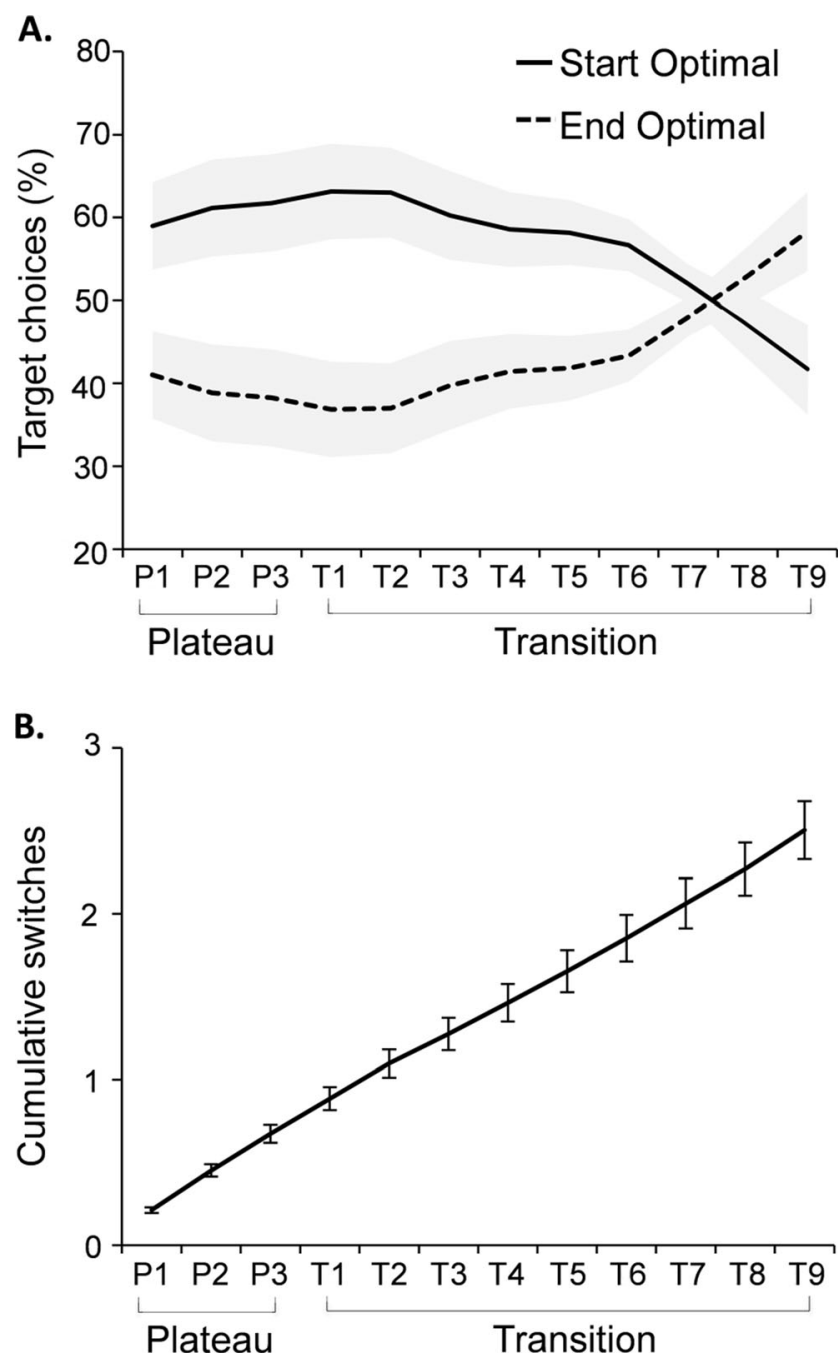

Fig. 3 a Percentage of target choices at each position along the run. The Start Optimal target is the target that was most optimal on the plateau and at the beginning of the transition. The End Optimal target was most optimal at the end of transition. Error bands depict standard error of the mean differences between Start and End Optimal at each position in the run. b Cumulative number of switches across the run. Error bars show standard error of the mean

results show that, to at least some extent, participants were maximizing performance.

Nevertheless, participants made many inefficient choices. Although they selected the optimal target most often, they selected the nonoptimal target on $39 \%$ of plateau trials. This is a substantial proportion, considering that RTs to nonoptimal targets were $479 \mathrm{~ms}$ slower than RTs to optimal targets, $t(42)=6.44, p<0.001, d=0.99$. Moreover, the pattern of choices across the transition also revealed a clear delay in the point at which participants switched over between target colors. Specifically, while participants began the transition favoring the start optimal color, they showed a clear preference for this color through position T6 in the transition (all $t \mathrm{~s}>4.17$, all $p \mathrm{~s}<0.001)$. Objectively, the two target colors become equally optimal at the midpoint of the transition 
(position T5), and the performance maximization account thus predicts that participants should switch by T6 in the transition. However, only at position $\mathrm{T} 7$ and $\mathrm{T} 8$ did choice rates for the two target colors even converge $(t(42)=1.72, p=0.093$, $d=0.26)$ and $(t(42)=1.70, p=0.098, d=0.26)$, respectively. Participants finally switched over to preferring the end optimal color at position T9 in the transition, $t(42)=3.47, p=0.001$, $d=0.53$, three trials after the point predicted by performance maximization.

The switchover delay can be explained by effort minimization. In particular, the results are consistent with a reactive control strategy, by which attentional control settings are only updated after performance has noticeably declined. However, it also is possible that the delayed switchover in choice could be explained by perceptual priming (Maljkovic \& Nakayama, 1994). For instance, after finding a red target for several trials in a row, the visual system could more efficiently detect red on the next trial. To address this concern, we can turn to the instructed search task; because participants in that task searched for the same color across entire blocks, perceptual priming should be as strong or stronger than in the adaptive choice task. Within this instructed task, we looked specifically at the RTs in the Start Optimal condition, where the target is optimal at the start of the transition and gradually becomes less optimal, because this is most similar to the progression we expect in the choice task. The results suggest that there may indeed be some priming effect; response times remained relatively flat up until position $\mathrm{T} 6$, one position after the midpoint (no main effect of position, $F(5,205)=1.00, p=0.42$, $\left.\eta_{\mathrm{p}}{ }^{2}=0.02\right)$. However, performance slowed significantly from position T6 to $\mathrm{T} 7, t(41)=4.88, p<0.001, d=0.82$, showing that search for the start-optimal color had become costly by this point. Therefore, even if the adaptive choice task had some priming component, performance maximization would predict a switchover by position $\mathrm{T} 7$ in the transition; that is, priming cannot fully explain the switchover being delayed until T9. Rather, some degree of effort minimization likely determined the sluggishness of the switchover.

Target switching According to a performance maximization account, optimal behavior requires regular and strategic updating of the attentional set. Observers should switch between targets once per run, during the transition. Alternatively, a desire to minimize effort may lead individuals to avoid switching on some runs, resulting in switch rates lower than once per run. Surprisingly, we found that participants switched 2.5 times per run, significantly more than once per run, $t(42)=8.60, p<0.001, d=1.31$. These unnecessary switches incurred a significant switch cost of $538 \mathrm{~ms}, t(42)=12.43$, $p<0.001, d=2.30$. Analysis of cumulative switches across the run shows that switches occurred even on plateaus and early in the transition (Fig. 3b). Specifically, participants switched on $22 \%$ of plateau trials, and almost half of these involved switching from an optimal target on trial N-1 to nonoptimal target on trial $\mathrm{N}$. This unnecessary and inefficient switching behavior cannot be explained by either performance maximization or effort minimization.

Why did participants switch so frequently? We first speculated that some of the switching, particularly switches from an optimal to a nonoptimal target, may have been opportunistic. Specifically, participants could have intended to search for one target but happened to fixate the other target accidentally in the search process. We might expect this to occur if the target appeared at a spatially advantageous location, either closer to the location of the target on the previous trial, or closer to fixation. However, we found no evidence for the former: distance between the current and previous target was the same for switch and repeat trials, $t \mathrm{~s}<1, p \mathrm{~s}>0.8$. Nevertheless, distance from fixation did have some influence on switching, Specifically, for trials in which participants switched from an optimal to a nonoptimal target, targets tended to be located closer to fixation than on trials in which participant repeated searching for the optimal target, $t(43)=2.11, p=0.04, d=0.44$. Thus, at least some of the switches may have been opportunistic, due to spatial proximity of the target from fixation.

\section{Fixation data}

Another possibility for the high rate of nonoptimal choices and frequent switching is that rather than searching selectively for one color within a trial, participants searched through both red and blue items until they found a target. Recent work has shown that when observers are foraging for multiple color targets (e.g., red and green amongst blue and yellow), they will switch frequently between the two targets, indicating that they are foraging for both simultaneously (Kristjánsson et al., 2014). We used the eye-tracking data to assess which colored items were being fixated within a given trial. If participants switched between the two target colors within a trial, we should see that fixations for both targets were relatively equal.

To analyze the eye-tracking data, each fixation falling within the search display range was assigned to the closest item. This method is open to some error, particularly if participants do not directly fixate the items that they are processing (i.e., if they fixate in between a cluster of items of interest), or if there is drift in the eye-tracking. Using this method, fixation was assigned to the target on $74.6 \%$ of trials on which the target was correctly identified, suggesting that there may be up to $25 \%$ error in the fixation allocations. (Note that we also median-split participants based on the proportion of trials in which a fixation was assigned to the target, and we reran the analyses using only those participants higher than the median. Mean target fixation was now $92.3 \%$, and the pattern of results was the same as described below.)

For simplicity, the analyses were restricted to the plateau trials, which contained only three colors (red, blue, and green). 
One participant's eye tracking data failed to record, leaving 42 participants. We calculated the proportion of fixations made to the items matching the color of the target that participants ultimately chose (chosen target color), the color of the target that participants did not choose (nonchosen target color), and the irrelevant green items. The values were then corrected for the number of items of each color, simply by dividing the total proportion to a given color by the number of items in that color. This was to control for the fact that there were always more items matching the nonoptimal color, and chance fixations were more likely to land on these items.

The fixation data are presented in Fig. 4. Overall, the proportion of fixations to the chosen target color and nonchosen target color were both higher than fixations to the irrelevant green items (all $p s<0.006$ ), as shown in Fig. 4a. However, the majority of fixations were to chosen target colored items, both when the optimal target color was chosen, $t(41)=13.66$, $p<0.001, d=2.11$, and when the nonoptimal target was chosen, $t(41)=11.68, p<0.001, d=1.80$. Furthermore, analyses of the first fixation on a trial (Fig. 4b) showed that participants

A.

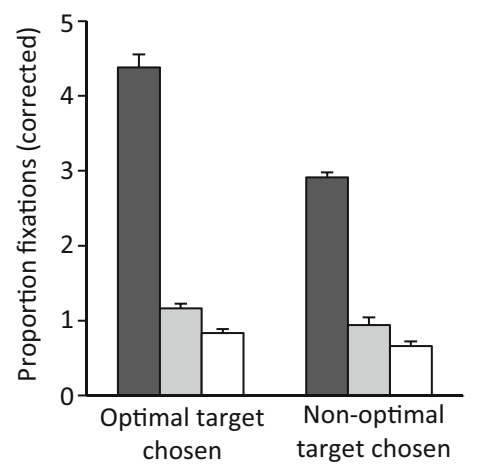

\section{B.}

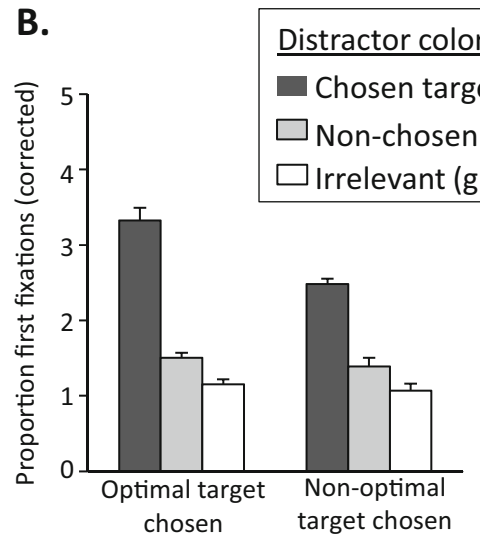

Fig. 4 Proportion of (a) total fixations within a trial, and (b) first fixations, to items matching the chosen target color, the nonchosen target color, and the irrelevant green items. Proportions are for plateau trials only and are corrected for the number of items of each color. Values are plotted separately for trials in which the optimal target was chosen and trials in which the nonoptimal target was chosen. Error bars depict standard error of the mean were most likely to fixate the chosen target color first, both when the optimal target color was chosen, $t(41)=7.97$, $p<0.001, d=1.23$, and when the nonoptimal target was chosen, $t(41)=6.08, p<0.001, d=0.94$. Together, these results suggest that participants usually chose the target color before the trial began and restricted search to items matching that chosen color.

\section{Effects of experience}

We also addressed the possibility that the inefficient behavior was due to inexperience with the task. Performance maximization may only emerge after significant experience with the changing environment, so we assessed the effect of experience by comparing performance in the first and second half of the experiment. Results showed that the proportions of target choices did not change from the first to the second half of the experiment (no main effect of half, $F(1,42)=2.12$, $p=0.15, \eta_{\mathrm{p}}{ }^{2}=0.05$, and no half by run position interaction, $\left.F(11,462)=0.86, p=0.58, \eta_{\mathrm{p}}{ }^{2}=0.02\right)$. Additionally, there was no change to the cumulative switches (no main effect, $F(1,42)=1.33, p=0.26, \eta_{\mathrm{p}}{ }^{2}=0.03$, and no interaction, $F(11$, $\left.462)=1.05, p=0.40, \eta_{\mathrm{p}}{ }^{2}=0.02\right)$.

\section{Individual differences}

The results of the group data suggest that both performance maximization and effort minimization contributed to participants' strategies. However, neither factor can explain the high rate of switching. In an attempt to understand the source of the inefficient behavior, we examined how individual participants' behavior differed based on the strategy they reported using. Analysis of 35 self-reports ( 8 did not provide sufficient information to determine strategy use) showed that selfreported strategies could be classified into three distinct groups. The first group $(N=17)$ reported searching for the target that had the fewest distractors or appeared most dissimilar to the distractors. We call this group Performance Maximizers. The second group, Effort Minimizers $(N=8)$, reported searching for a single color for an extended period and avoiding switching between colors. The third group, termed Random Searchers $(N=10)$, reported having no specific strategy and choosing "on the fly," or choosing the first color they saw.

Figure 5 shows striking differences in the pattern of results across the three groups. Analyses of target choices showed a significant interaction between choices at each position in the run and group, $F(22,352)=10.24, p<0.001, \eta_{\mathrm{p}}{ }^{2}=0.39$. Consistent with their reports, performance maximizers were significantly more likely to choose the optimal target color over the nonoptimal target color (73\% optimal vs. $27 \%$ nonoptimal on plateaus, $t(16)=5.78, p<0.001, d=1.40)$. In contrast, there was no preference for optimal over non-optimal 
A.

Performance Maximizers $(\mathrm{N}=17)$

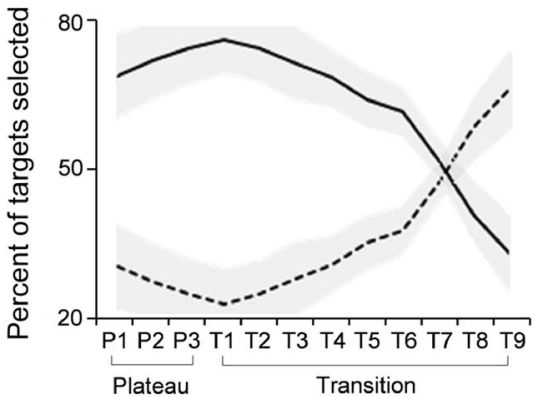

Random Searchers

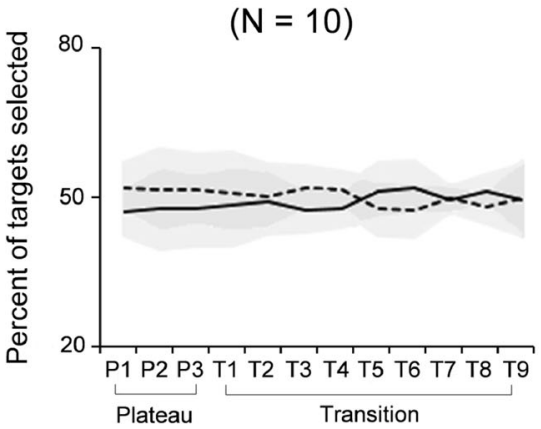

Fig. 5 a Percentage of target choices at each position in the run, plotted separately for the three self-reported strategy groups. Error bands show standard error of the mean difference scores at each position in the run. b targets for effort minimizers ( $52 \%$ optimal vs. $48 \%$ nonoptimal on plateaus, $t(7)=.56, p=0.59, d=0.20)$ or random searchers (45\% optimal vs. $55 \%$ nonoptimal on plateaus; $t(9)=1.45, p=0.18, d=0.46)$, suggesting that neither of these groups were motivated to maximize performance.

Switching frequency also varied considerably across groups, $F(2,32)=5.80, p=0.011, \eta_{\mathrm{p}}^{2}=0.25$. Effort minimizers switched least frequently (1.65 times per run), consistent with their reported desire to avoid switching. Performance maximizers switched an intermediate amount (2.37 per run), and random searchers switched most often (3.25 per run).

Performance by random searchers was surprisingly inefficient; they showed no preference toward the optimal target, and they also exhibited frequent switching. Their overall RT $(M=2157 \mathrm{~ms})$ was numerically slower than the other two groups (performance maximizers $M=1978$; effort minimizers $M=2025)$, most likely due to the added costs of their frequent switching. However, this was not significant, $F(2,32)=0.54$, $p=0.59, \eta_{\mathrm{p}}{ }^{2}=0.03$. Their inefficient choices did not seem to be due to poor visual search ability. In the instructed control task, where target identity was fixed, random searchers $(M=2559 \mathrm{~ms})$ were not slower overall than the other two groups (performance maximizers $M=2505 \mathrm{~ms}$; effort minimizers $\left.M=2573 ; F(2,31)=0.62, p=0.54, \eta_{\mathrm{p}}{ }^{2}=0.04\right)$.
Effort Minimizers

$(\mathrm{N}=8)$

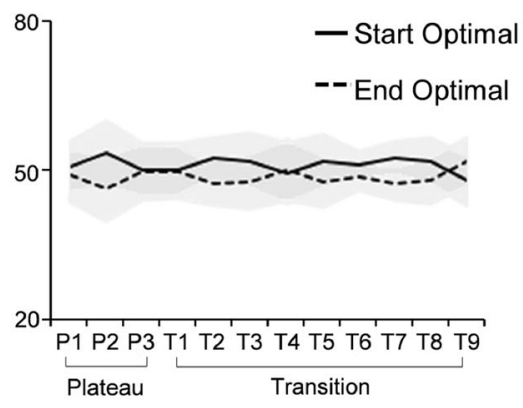

B. $\quad$....Random Searchers

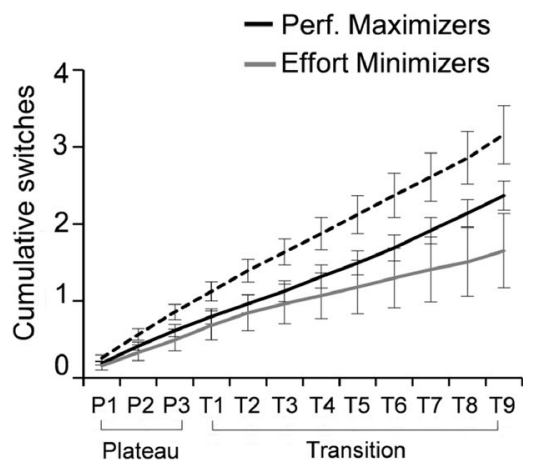

Cumulative number of switches along the runs for the three strategy groups. Error bars indicate standard error of the mean

Additionally, there was no difference in working memory capacity across the three groups, $F(2,31)=0.04, p=0.96$, $\eta_{\mathrm{p}}{ }^{2}=0.003$. The pattern of fixations also was very consistent across the three groups; there were no interactions between the three groups in the proportion of items fixated within trials (all $p \mathrm{~s}>0.20$ ), or the color of the first fixation (all $p \mathrm{~s}>0.38$ ), suggesting that the random searchers were no more likely to switch between target colors within trials than the other groups. There was, however, some tentative evidence that random searchers may be higher on trait impulsivity. Scores on the BIS-11 were numerically higher for this group $(M=65.50)$ than for the other two groups (performance maximizers $M=58.39$; effort minimizers $M=59.80$ ), although the difference across groups was not significant, $F(2,32)=1.68$, $p=0.20, \eta_{\mathrm{p}}{ }^{2}=0.10$.

In addition to looking at participants' strategies, we also looked at their self-reported awareness of the changing environment. Surprisingly, this had very little impact on performance. Only seven participants reported being aware that the distractor colors changed from red through purple to blue. These participants were no more likely to choose the optimal target. The mean rate of choosing the optimal target was $54 \%$ for aware participants and $63 \%$ for unaware participants, $t(36)=1.17, p=0.25, d=0.56)$, and the pattern of choices 
across the full run did not vary between the two groups, $F(11$, 396) $=0.83, p=0.61, \eta_{\mathrm{p}}{ }^{2}=0.02$. Similarly, the rate of switching was equivalent across the two groups, $t(36)=0.35$, $p=0.73, d=16$. We also found no correlation between working memory capacity and the proportion of target choices $(r=0.20, p=0.21)$ or switch frequency $(r=0.06, p=0.69)$. The same was true for trait impulsivity (correlation with choice data: $r=0.10, p=0.54$; correlation with switch frequency: $r=-0.08, p=0.62$ ).

Finally, we examined whether an individual's performance on the choice task could be predicted by their performance on the instructed and the cued switching task. We speculated that on the instructed search task, participants who experienced a greater RT cost for the nonoptimal target would be more likely to choose the optimal target on the choice task. However, the RT cost in the instructed visual search task (on plateaus) did not correlate with the proportion of optimal target choices (also on plateaus, $r=0.02, p=0.88$ ). Additionally, we examined whether a person's propensity to avoid switching depended on their switch cost. Kool et al. (2010) found that individuals with larger switch costs on a control task were more likely to avoid switching; however, other studies using voluntary task switching found no such correlation (Arrington \& Yates, 2009; Butler, Arrington \& Weywadt, 2011). Our results were consistent with these latter findings; we found no significant correlation between the size of the switch cost on the cued switching task and frequency of switching on the choice task $(r=0.17, p=0.27)$.

\section{General discussion}

The question of how we configure goal-directed control has been largely neglected in the attention literature. We introduced a new method, adaptive choice visual search, to begin to explore how individuals choose attentional control settings in a changing environment. The method has three key features. First, it allows participants to freely choose one of two targets on every trial. Second, while keeping the targets constant, it manipulates the relative difficulty of finding the two targets by cyclically changing the distractor makeup across trials. Finally, in addition to allowing conventional measures of RT and accuracy, this method features choice as its key dependent measure of interest.

The main finding of this study was that choice behavior was far from optimal. There was evidence for some performance maximization: the optimal target was selected more frequently than the nonoptimal target. However, when we looked at individual performance, we found that only about half of the group reported using the performance maximization strategy, and the remaining participants showed no evidence for performance maximization whatsoever. Moreover, even those who reported using the strategy nevertheless engaged in inefficient behavior, such as delaying switching to the new target and making frequent, unnecessary switches. These results challenge assumptions about how individuals strategically use their control settings in unconstrained environments; even if people possess the capacity to use an optimal strategy (as demonstrated here by the instructed task), they often fail to do so.

How can we explain the inefficient choices? To some extent, we support the hypothesis that individuals are driven to minimize cognitive effort. We predicted that if participants were motivated to minimize effort, they would be less likely to sustain an effortful proactive control strategy; instead, they would fall back on using reactive control (Braver et al., 2007; Chatham et al., 2009; Locke \& Braver, 2008). Consistent with this, even the participants who reported a performance maximization approach delayed updating their attentional control settings during the transition. The switchover to the new target did not occur until a few trials after search with the old target had become inefficient. A number of participants also reported that their decision to switch targets was triggered by the sense that searching for the old target was taking too long and required searching through too many distractors. One could argue that the cumulative RT costs of delaying the switchover in strategy were actually relatively minor in the grand schemea fraction of a second every run of trials and perhaps $30 \mathrm{sec}-$ onds total in an hour-long experiment. Contrast this with the likely metabolic costs of maintaining a proactive strategy for the entire session.

We also hypothesized that effort minimization would reduce the frequency with which individuals updated their attentional control settings (Kool et al., 2010). We found mixed results. One subgroup of participants, the effort minimizers, reported choosing to avoid switching between targets. This was reflected in their switch rate, which was lower than the other subgroups. However, all participants switched significantly more than the optimal rate (once per transition), and they frequently switched from an optimal to a nonoptimal target, even during the plateaus. This finding could be explained by neither performance maximization nor effort minimization. It also is surprising, given two previous observations. First, researchers have documented a perseverative bias in voluntary task switching, where individuals who are instructed to switch approximately $50 \%$ of the time routinely fall short of this instruction (Arrington \& Logan, 2004). Second, when given a choice between a series of trials that consists of frequent versus infrequent task switching, participants largely choose the latter (Kool et al., 2010). In our study, some of this switching may have been opportunistic: we found that on trials in which participants switched to the nonoptimal color, the target was located somewhat closer to fixation than on optimal repeat trials. However, the first fixation on nonoptimal switch trials was still most likely to fall on a distractor matching the nonoptimal color, indicating that on many trials, 
the switch to the nonoptimal color had been made before the target was detected. The frequent switching could not be explained by a lack of awareness of the environment, because participants who reported awareness of the variable color's oscillatory pattern showed the same switch rates as those without awareness. Moreover, switch rates did not decline with practice (i.e., in the second half of the experiment).

Instead, we speculate that the high rate of switching may be motivated by a novelty-seeking drive. Novel stimuli attract attention, even when they are task-irrelevant (Becker \& Horstmann, 2011; Horstmann, 2002; Retell, Becker \& Remington, 2015), and attending to novel items is associated with an increased dopaminergic response (Kakade \& Dayan, 2002). Some have argued that novelty-seeking serves to promote exploration, a process whereby an organism samples new and task-irrelevant stimuli with the goal of finding new rewards in the environment (Aston-Jones \& Cohen, 2005; Kakade \& Dayan, 2002). Exploration is functionally very important-it allows an organism to keep tabs on events occurring outside of its present task, and it prevents perseveration of strategies that are no longer effective (Hills et al., 2015). The consequence, however, is that even effective goal-directed strategies will occasionally be overridden by novelty-seeking.

Although the current study does not allow us to test the novelty-seeking hypothesis directly, we note that the random searchers subgroup, which had the highest rate of switching, also had the numerically highest mean trait impulsivity, as measured by the Barratt Impulsiveness Scale (Patton, et al., 1995). This scale has long served as survey measure of novelty seeking and is correlated with behavioral indices of risk taking and sensation seeking (Roberti, 2004). Nevertheless, more research will be required to determine whether the irrelevant switching in the current study was due to a novelty-seeking drive, and in turn, how novelty seeking might influence goal-directed control.

Of course, there are potential alternatives to the noveltyseeking hypothesis. The high rate of switching observed in the random searchers group could have occurred involuntarily, as the result of internal noise in the information processing and decision-making systems (Kessler, Shencar, \& Meiran, 2009). Switching also may signal uncertainty in the target choice process. Uncertainty in decision-making often is associated with slowed decisions, vacillation between options, and choice inconsistency (Busemeyer \& Townsend, 1993; Yoshida \& Ishii, 2006). In our study, both performance maximizers and effort minimizers used a specific strategy to guide their choices - either choosing the color expected to have the fewest distractor, or repeating the same choice on every trialand this may have mitigated decision uncertainty. Random searchers, however, did not use a clear strategy, and therefore may have experienced more uncertainty, resulting in inconsistent choices and frequent switching. If so, switch rates may be reduced if participants are encouraged to adopt a specific strategy to guide their choices.

\section{Methodological advances}

In addition to the main empirical findings of this study, we also must emphasize the methodological advances of the adaptive choice visual search procedure. First, the focus on choice as our main dependent measure of interest is unique in the attention literature, which has traditionally focused heavily on RT and accuracy measures. By allowing self-generated choice during a task in which multiple options were available to the participants, we were able to measure a variety of strategic approaches toward the task. Note that we are surely not the first to assess the use of attentional control settings when multiple strategies are available (Bacon \& Egeth, 1994; 1997; Cosman \& Vecera, 2013; Leber \& Egeth, 2006a, b; Kawahara, 2010). However, in studies like these, assessing attentional control settings requires aggregating data across multiple trials. By presenting two targets on each trial and accurately measuring which target was chosen, we are able to infer with a high degree of confidence which attentional setting is configured on each trial. This paradigm thus enables fine-grained measurements of changes in attentional control on a trial-bytrial basis, perhaps more precisely than has been done previously (Leber, 2010).

A second key methodological advance is the use of a constantly changing external environment, which gradually varies the efficiency of using one control setting versus another. This method is conceptually similar to a manipulation by Fougnie, Cormiea, Zhang, Alvarez, and Wolfe (2015), who gradually varied the frequency of targets in a visual foraging task. Our method of varying the relative difficulty of two control settings is not only new to the attention literature, but it overcomes inherent limitations to studying task choice in the broader cognitive control literature. For example, the voluntary task switching procedure was designed to assess free choice in the shifting of cognitive task set (Arrington \& Logan, 2004). However, switching in this task is generally based only on the artificial constraint that participants switch on half of the trials. There is no external information to signal which of the two tasks is most appropriate. In the present paradigm, participants are truly free to select the most subjectively desirable strategy on each trial, without constraints. Thus, the use of a variable external environment could potentially be applied beneficially to domains outside the realm of attention.

\section{Future directions}

This initial study using the adaptive control visual search task establishes fertile ground for several follow-up questions. For this first experiment, we chose a relatively low-level form of goal-directed control and a simple choice process (i.e., the choice between two basic features). However, real-life search behavior may involve using more complex attentional 
strategies, and future work with this paradigm could be extended to higher-level control settings (e.g., settings for object category), as well as domains outside of the attention literature (e.g., task switching or more complex decision making). Future versions of the task should also examine the extent to which past experience influences performance. When participants in the current study completed the choice task, they had already completed two control visual search tasks. Presenting the tasks in the same order for all participants enabled us to address individual differences, but this also prevented us from assessing the effects of prior experience. It is possible that the control tasks gave participants more opportunity to learn about the changing environment and its influence on search times and to use this learning on the choice task. Alternatively, some of the search behaviors in the control tasks (i.e., searching for a single color for an extended period of time in the instructed task, or frequent switching in the cued switch task) may have carried over to the choice task (Leber \& Egeth 2006a, 2006b; Leber et al., 2009), reducing optimal search. Subsequent studies also should address the role of instruction. In the current study, participants were informed in advance that the ratio of red to blue distractor would change and that they may find it easier to search for the less prevalent colors. Such instructions may encourage a performance maximization strategy. Interestingly, the presence of these instructions makes it even more surprising that we found such a high rate of nonoptimal behavior and suggests that the rates of performance maximization may be even lower when participants receive very little instruction.

A final question concerns the factors underlying individual differences in strategy choice. Our finding that impulsivity was somewhat higher in random searchers suggests that certain personality traits may predict strategy choice. For example, performance maximizers and effort minimizers may differ in the extent to which they are willing to engage in cognitively effortful tasks (cf. "Need for Cognition"; Cacioppo \& Petty, 1982). Strategy use may depend on an individual's cognitive abilities. Maintaining a proactive control strategy adds an additional cognitive load, which has been shown to influence various types of task performance (Lavie, Hirst, de Fockert, \& Viding, 2004; Woodman \& Luck, 2004). Individuals who suffer the greatest task impairments while attempting to maintain proactive control could be the most prone to abandon performance maximization in favor of other strategies. This seems unlikely in the present experiment, because we found no difference between the three groups on working memory capacity, which, although not a direct measure of a performance under cognitive load, is correlated with IQ and executive functioning (Cowan et al., 2005; Miyake, Friedman, Rettinger, Shah \& Hegarty, 2001). Additionally, there was no evidence that effort minimizers and random searchers ever attempted a performance maximizing strategy. Even in first block of trials, both groups selected the non-optimal target as often as the optimal target (53\% vs. $47 \%$ of trials). Nevertheless, it is possible that in some situations and for some individuals, the performance maximization strategy that we have specified might not actually be the optimal choice, and an interesting approach for future research may be to assess the extent to which optimal strategies are dependent on individual differences.

\section{Conclusion}

A new paradigm — adaptive choice visual search — has yielded interesting new insights into how individuals balance between multiple motivational drives in choosing their attentional control settings. We have produced some evidence that individuals seek to maximize performance and minimize effort, although there are broad differences across individuals in the extent to which the two strategies drive performance. In addition, focusing on these two strategies cannot tell the complete story, because other motivators, such as novelty seeking, are likely present when individuals are free to choose how they search. Our adaptive choice paradigm is only in its infancy, and future work with it will be further aimed at fully understanding how goal-directed attentional control is chosen.

Acknowledgments We dedicate this article to Steven Yantis, a brilliant, rigorous, and kind researcher who was the quintessential academic role model. His contributions to the literature on attentional control formed a solid foundation of empirical knowledge, theory, and methodology, which has fundamentally impacted our present research questions and experimental approach. We also thank four anonymous reviewers for insightful comments and suggestions.

\section{References}

Adamo, M., Wozny, S., Pratt, J., \& Ferber, S. (2010). Parallel, independent attentional control settings for colors and shapes. Attention, Perception \& Psychophysics, 72, 1730-1735. doi:10.3758/APP.72.7.1730

Anderson, B. A., \& Folk, C. L. (2010). Variations in the magnitude of attentional capture: Testing a two-process model. Attention, Perception \& Psychophysics, 72, 342-352. doi:10.3758/APP.72.2.342

Anderson, B. A., Laurent, P. A., \& Yantis, S. (2011). Value-driven attentional capture. Proceedings of the National Academy of Sciences, 108, 10367-10371. doi:10.1073/pnas.1104047108

Ansorge, U., \& Heumann, M. (2003). Top-down contingencies in peripheral cueing: The roles of color and location. Journal of Experimental Psychology: Human Perception and Performance, 29, 937-948. doi:10.1037/0096-1523.29.5.937

Ansorge, U., \& Horstmann, G. (2007). Preemptive control of attentional capture by colour: Evidence from trial-by-trial analyses and orderings of onsets of capture effects in reaction time distributions. The Quarterly Journal of Experimental Psychology, 60, 952-975. doi: 10.1080/17470210600822795

Ansorge, U., Horstmann, G., \& Carbone, E. (2005). Top-down contingent capture by color: Evidence from RT distribution analyses in a manual choice reaction task. Acta Psychologica, 120, 243-266. doi:10. 1016/j.actpsy.2005.04.004 
Araujo, C., Kowler, E., \& Pavel, M. (2001). Eye movements during visual search: The costs of choosing the optimal path. Vision Research, 41, 3613-3625. doi:10.1016/S0042-6989(01)00196-1

Ariga, A., \& Yokosawa, K. (2008). Contingent attentional capture occurs by activated target congruence. Perception \& Psychophysics, 70, 680-687. doi:10.3758/PP.70.4.680

Arrington, C. M., \& Logan, G. D. (2004). The cost of a voluntary task switch. Psychological Science, 15, 610-615. doi:10.1111/j.09567976.2004.00728.x

Arrington, C. M., \& Yates, M. M. (2009). The role of attentional networks in voluntary task switching. Psychonomic Bulletin \& Review, 16, 660-665. doi:10.3758/PBR.16.4.660

Aston-Jones, G., \& Cohen, J. D. (2005). An integrative theory of Locus Coeruleus-Norepinephrine function: Adaptive gain and optimal performance. Annual Review of Neuroscience, 28, 403-450. doi:10. 1146/annurev.neuro.28.061604.135709

Atchley, P., Kramer, A. F., \& Hillstrom, A. P. (2000). Contingent capture for onsets and offsets: Attentional sets for perceptual transients. Journal of Experimental Psychology: Human Perception and Performance, 26, 594-606. doi:10.1037/0096-1523.26.2.594

Bacon, W. F., \& Egeth, H. E. (1994). Overriding stimulus-driven attentional capture. Perception \& Psychophysics, 55, 485-496. doi:10. 3758/BF03205306

Bacon, W. F., \& Egeth, H. E. (1997). Goal-directed guidance of attention: Evidence from conjunctive visual search. Journal of Experimental Psychology: Human Perception and Performance, 23, 948. doi:10. 1037/0096-1523.23.4.948

Barnard, P. J., Scott, S., Taylor, J., May, J., \& Knightley, W. (2004). Paying attention to meaning. Psychological Science, 15, 179-186. doi:10.1111/j.0956-7926.2004.01503006.x

Barrett, D. J., \& Zobay, O. (2014). Attentional control via parallel targettemplates in dual-target search. PloS ONE, 9(1), e86848. doi:10. 1371/journal.pone. 0086848

Beck, V. M., Hollingworth, A., \& Luck, S. J. (2012). Simultaneous control of attention by multiple working memory representations. Psychological Science, 23, 887-898. doi:10.1177/0956797612439068

Becker, S. I. (2008). Can intertrial effects of features and dimensions be explained by a single theory? Journal of Experimental Psychology: Human Perception and Performance, 34, 1417-1440. doi:10.1037/ a0011386

Becker, S. I. (2010). The role of target-distractor relationships in guiding attention and the eyes in visual search. Journal of Experimental Psychology: General, 139, 247-265. doi:10.1037/a0018808

Becker, S. I., Folk, C. L., \& Remington, R. W. (2013). Attentional capture does not depend on feature similarity, but on target-nontarget relations. Psychological Science, 24, 634-647. doi:10.1177/ 0956797612458528

Becker, S. I., \& Horstmann, G. (2011). Novelty and saliency in attentional capture by unannounced motion singletons. Acta Psychologica, 136, 290-299. doi:10.1016/j.actpsy.2010.12.002

Bergen, J. R., \& Julesz, B. (1983). Parallel versus serial processing in rapid pattern discrimination. Nature, 303, 696-698. doi:10.1038/ 303696a0

Bettman, J. R., Johnson, E. J., \& Payne, J. W. (1990). A componential analysis of cognitive effort in choice. Organization Behavior and Human Decision Processes, 45, 111-139. doi:10.1016/07495978(90)90007-V

Boot, W. R., Becic, E., \& Kramer, A. F. (2009). Stable individual differences in search strategy?: The effect of task demands and motivational factors on scanning strategy in visual search. Journal of Vision, 9(3), 7.1-16. doi:10.1167/9.3.7

Boot, W. R., Kramer, A. F., Becic, E., Wiegmann, D. A., \& Kubose, T. (2006). Detecting transient changes in dynamic displays: The more you look, the less you see. Human Factors, 48, 759-773. doi:10. $1518 / 001872006779166424$
Botvinick, M., \& Braver, T. (2015). Motivation and cognitive control: From behavior to neural mechanism. Annual Review of Psychology, 66, 83-113. doi:10.1146/annurev-psych-010814-015044

Botvinick, M. M., Braver, T. S., Barch, D. M., Carter, C. S., \& Cohen, J. D. (2001). Conflict monitoring and cognitive control. Psychological Review, 108(3), 624-652. doi:10.1037/0033-295X.108.3.624

Botvinick, M. M., \& Rosen, Z. B. (2009). Anticipation of cognitive demand during decision-making. Psychological Research, 73, 835-842. doi:10.1007/s00426-008-0197-8

Brainard, D. H. (1997). The Psychophysics Toolbox. Spatial Vision, 10, 433-436. doi:10.1163/156856897X00357

Braver, T. S. (2012). The variable nature of cognitive control: A dual mechanisms framework. Trends in Cognitive Sciences, 16, 106113. doi:10.1016/j.tics.2011.12.010

Braver, T. S., Gray, J. R., \& Burgess, G. C. (2007). Explaining the many varieties of working memory variation: Dual mechanisms of cognitive control. In A. R. A. Conway, C. Jarrold, M. C. Kane, A. Miyake, \& J. N. Towse (Eds.), Variation in working memory (pp. 76-106). New York: Oxford University Press.

Busemeyer, J. R., \& Townsend, J. T. (1993). Decision field theory: A dynamic-cognitive approach to decision making in an uncertain environment. Psychological Review, 100, 432-459. doi:10.1037/ 0033-295X.100.3.432

Butler, K. M., Arrington, C. M., \& Weywadt, C. (2011). Working memory capacity modulates task performance but has little influence on task choice. Memory \& Cognition, 39, 708-724. doi:10.3758/ s13421-010-0055-y

Cacioppo, J. T., \& Petty, R. E. (1982). The need for cognition. Journal of Personality and Social Psychology, 42, 116-131. doi:10.1037/ 0022-3514.42.1.116

Cain, M. S., Vul, E., Clark, K., \& Mitroff, S. R. (2012). A Bayesian optimal foraging model of human visual search. Psychological Science, 23, 1047-1054. doi:10.1177/0956797612440460

Chatham, C. H., Frank, M. J., \& Munakata, Y. (2009). Pupillometric and behavioral markers of a developmental shift in the temporal dynamics of cognitive control. Proceedings of the National Academy of Sciences, 106, 5529-5533. doi:10.1073/pnas.0810002106

Cosman, J. D., \& Vecera, S. P. (2013). Context-dependent control over attentional capture. Journal of Experimental Psychology: Human Perception and Performance, 39, 836-848. doi:10.1037/a0030027

Cowan, N. (2001). The magical number 4 in short-term memory: A reconsideration of mental storage capacity. Behavioral and Brain Sciences, 24, 87-114. doi:10.1017/S0140525X01003922

Cowan, N., Elliott, E. M., Saults, J. S., Morey, C. C., Mattox, S., Hismjatullina, A., \& Conway, A. R. (2005). On the capacity of attention: Its estimation and its role in working memory and cognitive aptitudes. Cognitive Psychology, 51, 42-100. doi:10.1016/j. cogpsych.2004.12.001

Davis, G. J., \& Gibson, B. S. (2012). Going rogue $n$ the spatial cuing paradigm: High spatial validity is insufficient to elicit voluntary shifts of attention. Journal of Experimental Psychology: Human Perception and Performance, 38, 1192-1201. doi:10.1037/ a0027595

Della Libera, C., \& Chelazzi, L. (2006). Visual selective attention and the effects of monetary rewards. Psychological Science, 17, 222-227. doi:10.1111/j.1467-9280.2006.01689.x

Donderi, D. C., \& Zelnicker, D. (1969). Parallel processing in visual same-different decisions. Perception \& Psychophysics, 5, 197200. doi:10.3758/BF03210537

Duncan, J., \& Humphreys, G. W. (1989). Visual search and stimulus similarity. Psychological Review, 96, 433-458. doi:10.1037/0033295X.96.3.433

Egeth, H. E., Leonard, C. J., \& Leber, A. B. (2010). Why salience is not enough: Reflections on top-down selection in vision. Acta Psychologica, 135, 130-132. doi:10.1016/j.actpsy.2010.05.012 
Egeth, H. E., Virzi, R. A., \& Garbart, H. (1984). Searching for conjunctively defined targets. Journal of Experimental Psychology: Human Perception and Performance, 10, 32. doi:10.1037/0096-1523.10.1.32

Egeth, H. E., \& Yantis, S. (1997). Visual attention: Control, representation, and time course. Annual Review of Psychology, 48, 269-297. doi:10.1146/annurev.psych.48.1.269

Eriksen, C. W., \& Hoffman, J. E. (1972). Temporal and spatial characteristics of selective encoding from visual displays. Perception \& Psychophysics, 12, 201-204. doi:10.3758/BF03212870

Folk, C. L., \& Anderson, B. A. (2010). Target-uncertainty effects in attentional capture: Color-singleton set or multiple attentional control settings? Psychonomic Bulletin \& Review, 17, 421-426. doi:10. 3758/PBR.17.3.421

Folk, C. L., Leber, A. B., \& Egeth, H. E. (2002). Made you blink! Contingent attention capture produces a spatial blink. Attention, Perception \& Psychophysics, 64, 741-753. doi:10.3758/ BF03194741

Folk, C. L., Leber, A. B., \& Egeth, H. E. (2008). Top-down control settings and the attentional blink: Evidence for nonspatial contingent capture. Visual Cognition, 16, 616-642. doi:10.1080/ 13506280601134018

Folk, C. L., \& Remington, R. W. (1998). Selectivity in distraction by irrelevant feature singletons: Evidence for two forms of attentional capture. Journal of Experimental Psychology: Human Perception and Performance, 24, 847-858. doi:10.1037/0096-1523.24.3.847

Folk, C. L., Remington, R. W., \& Johnston, J. C. (1992). Involuntary covert orienting is contingent on attentional control settings. Journal of Experimental Psychology: Human Perception and Performance, 18, 1030-1044. doi:10.1037/0096-1523.18.4.1030

Folk, C. L., Remington, R. W., \& Wright, J. H. (1994). The structure of attentional control: Contingent attentional capture by apparent motion, abrupt onset, and color. Journal of Experimental Psychology: Human Perception and Performance, 20, 317-329. doi:10.1037/ 0096-1523.20.2.317

Fougnie, D., Cormiea, S. M., Zhang, J., Alvarez, G. A., \& Wolfe, J. M. (2015). Winter is coming: How humans forage in a temporally structured environment. Journal of Vision, 15(11), 1.1-11. doi:10.1167/ 15.11 .1

Fukuda, K., \& Vogel, E. K. (2011). Individual differences in recovery time from attentional capture. Psychological Science, 22, 361-368. doi: $10.1177 / 0956797611398493$

Green, B. F., \& Anderson, L. K. (1956). Color coding in a visual search task. Journal of Experimental Psychology, 51, 19-24. doi:10.1037/ h0047484

Hills, T. T., Todd, P. M., Lazer, D., Redish, A. D., Couzin, I. D., \& Cognitive Search Research Group. (2015). Exploration versus exploitation in space, mind, and society. Trends in Cognitive Sciences, 19, 46-54. doi:10.1016/j.tics.2014.10.004

Horstmann, G. (2002). Evidence for attentional capture by a surprising color singleton in visual search. Psychological Science, 13, 499505. doi:10.1111/1467-9280.00488

Hull, C. L. (1943). Principles of behavior. New York: Appleton-Century.

Irons, J. L., Folk, C. L., \& Remington, R. W. (2012). All set! Evidence of simultaneous attentional control settings for multiple target colors. Journal of Experimental Psychology: Human Perception and Performance, 38, 758-775. doi:10.1037/a0026578

Itti, L., Koch, C., \& Niebur, E. (1998). A model of saliency-based visual attention for rapid scene analysis. IEEE Transactions on Pattern Analysis \& Machine Intelligence, 11, 1254-1259. doi:10.1109/34. 730558

Johnson, E. J., \& Payne, J. W. (1985). Effort and accuracy in choice. Management Science, 31, 395-414.

Kakade, S., \& Dayan, P. (2002). Dopamine: Generalization and bonuses. Neural Networks, 15, 549-559. doi:10.1016/S0893-6080(02) 00048-5
Kane, M. J., Bleckley, M. K., Conway, A. R., \& Engle, R. W. (2001). A controlled-attention view of working-memory capacity. Journal of Experimental Psychology: General, 130, 169-183. doi:10.1037/ 0096-3445.130.2.169

Kaptein, N. A., Theeuwes, J., \& Van der Heijden, A. H. C. (1995). Search for a conjunctively defined target can be selectively limited to a color-defined subset of elements. Journal of Experimental Psychology: Human Perception and Performance, 21, 1053-1069. doi:10.1037/0096-1523.21.5.1053

Kawahara, J. (2010). Identifying a "default" visual search mode with operant conditioning. Acta Psychologica, 135, 38-49. doi:10. 1016/j.actpsy.2010.05.002

Kessler, Y., Shencar, Y., \& Meiran, N. (2009). Choosing to switch: Spontaneous task switching despite associated behavioral costs. Acta Psychologica, 131, 120-128. doi:10.1016/j.actpsy.2009.03. 005

Kool, W., McGuire, J. T., Rosen, Z. B., \& Botvinick, M. M. (2010). Decision making and the avoidance of cognitive demand. Journal of Experimental Psychology: General, 139, 665-682. doi:10.1037/ a0020198

Kool, W., McGuire, J. T., Wang, G. J., \& Botvinick, M. M. (2013). Neural and behavioral evidence for an intrinsic cost of self-control. PloS One, 8, e72626. doi:10.1371/journal.pone.0072626

Kristjánsson, Á., Jóhannesson, Ó. I., \& Thornton, I. M. (2014). Common attentional constraints in visual foraging. PloS ONE, 9(6), e100752. doi:10.1371/journal.pone. 0100752

Lamy, D., Leber, A., \& Egeth, H. E. (2004). Effects of task relevance and stimulus-driven salience in feature-search mode. Journal of Experimental Psychology: Human Perception and Performance, 30, 1019-1031. doi:10.1037/0096-1523.30.6.1019

Lavie, N., Hirst, A., De Fockert, J. W., \& Viding, E. (2004). Load theory of selective attention and cognitive control. Journal of Experimental Psychology: General, 133, 339-354. doi:10.1037/0096-3445.133.3. 339

Leber, A. B. (2010). Neural predictors of within-subjects fluctuations in attentional control. The Journal of Neuroscience, 30, 11458-11465. doi:10.1523/JNEUROSCI.0809-10.2010

Leber, A. B., \& Egeth, H. E. (2006a). Attention on autopilot: Past experience and attentional set. Visual Cognition, 14, 565-583. doi:10. 1080/13506280500193438

Leber, A. B., \& Egeth, H. E. (2006b). It's under control: Top-down search strategies can override attentional capture. Psychonomic Bulletin \& Review, 13, 132-138. doi:10.3758/BF03193824

Leber, A. B., Kawahara, J., \& Gabari, Y. (2009). Long-term abstract learning of attentional set. Journal of Experimental Psychology: Human Perception and Performance, 35, 1385-1397. doi:10. 1037/a0016470

Leblanc, É., \& Jolicœur, P. (2007). Can capture of visuospatial attention be contingent on category? Behavioural and electrophysiological evidence. Visual Cognition, 15, 97-101. doi:10.1080/ 13506280600975486

Lien, M., Ruthruff, E., \& Johnston, J. C. (2010). Attentional capture with rapidly changing attentional control settings. Journal of Experimental Psychology: Human Perception and Performance, 36, 1-16. doi:10.1037/a0015875

Lien, M. C., Ruthruff, E., \& Naylor, J. (2014). Attention capture while switching search strategies: Evidence for a breakdown in top-down attentional control. Visual Cognition, 22, 1105-1133. doi:10.1080/ 13506285.2014.962649

Locke, H. S., \& Braver, T. S. (2008). Motivational influences on cognitive control: Behavior, brain activation, and individual differences. Cognitive, Affective, \& Behavioral Neuroscience, 8, 99-112. doi:10. 3758/CABN.8.1.99

Lorist, M. M., Boksem, M. A., \& Ridderinkhof, K. R. (2005). Impaired cognitive control and reduced cingulate activity during mental 
fatigue. Cognitive Brain Research, 24, 199-205. doi:10.1016/j. cogbrainres.2005.01.018

Luck, S. J., \& Vogel, E. K. (1997). The capacity of visual working memory for features and conjunctions. Nature, 390, 279-281. doi:10. $1038 / 36846$

Maljkovic, V., \& Nakayama, K. (1994). Priming of pop-out: I. Role of features. Memory \& Cognition, 22, 657-672. doi:10.3758/ BF03209251

Miyake, A., Friedman, N. P., Rettinger, D. A., Shah, P., \& Hegarty, M. (2001). How are visuospatial working memory, executive functioning, and spatial abilities related? A latent-variable analysis. Journal of Experimental Psychology: General, 130, 621-640. doi:10.1037/ 0096-3445.130.4.621

Moore, K. S., \& Weissman, D. H. (2010). Involuntary transfer of a topdown attentional set into the focus of attention: Evidence from a contingent attentional capture paradigm. Attention, Perception \& Psychophysics, 72, 1495-1509. doi:10.3758/APP.72.6.1495

Moore, K. S., \& Weissman, D. H. (2011). Set-specific capture can be reduced by pre-emptively occupying a limited capacity focus of attention. Visual Cognition, 19, 417-444. doi:10.1080/13506285. 2011.558862

Muraven, M., \& Baumeister, R. F. (2000). Self-regulation and depletion of limited resources: Does self-control resemble a muscle? Psychological Bulletin, 126, 247-259. doi:10.1037/0033-2909. 126.2.247

Najemnik, J., \& Geisler, W. S. (2005). Optimal eye movement strategies in visual search. Nature, 434, 387-391. doi:10.1038/nature03390

Navalpakkam, V., \& Itti, L. (2007). Search goal tunes visual features optimally. Neuron, 53, 605-617. doi:10.1016/j.neuron.2007.01.018

Navalpakkam, V., Koch, C., Rangel, A., \& Perona, P. (2010). Optimal reward harvesting in complex perceptual environments. Proceedings of the National Academy of Sciences, 107, 52325237. doi:10.1073/pnas.0911972107

Northdurft, H. C. (1993). The role of features in preattentive vision: Comparison of orientation, motion and color cues. Vision Research, 14, 1937-1958. doi:10.1016/0042-6989(93)90020-W

O'Leary, A., \& Sloutsky, V. M. (2016) Carving metacognition at its joints: Protracted development of component processes. Child Development

Pashler, H. (1988). Cross-dimensional interaction and texture segregation. Perception \& Psychophysics, 43, 307-318. doi:10.3758/ BF03208800

Patton, J. H., Stanford, M. S., \& Barratt, E. S. (1995). Factor structure of the Barratt impulsiveness scale. Journal of Clinical Psychology, 51, 768-774. doi:10.1002/1097-4679(199511)51:6<768::AIDJCLP2270510607>3.0.CO;2-1

Pauszek, J. R., \& Gibson, B. S. (2016). High spatial validity is not sufficient to elicit voluntary shifts of attention. Attention, Perception \& Psychophysics. Advance online publication. doi:10.3758/s13414 016-1097-4

Pelli, D. G. (1997). The VideoToolbox software for visual psychophysics: Transforming numbers into movies. Spatial Vision, 10, 447-466. doi: $10.1163 / 156856897 X 00366$

Posner, M. I., Nissen, M. J., \& Ogden, W. C. (1978). Attended and unattended processing modes: The role of set for spatial location. In H. L. Pick \& I. J. Saltzman (Eds.), Modes of Perceiving and Processing Information. Hillsdale: Lawrence Erlbaum Associates.

Proulx, M. J. (2011). Individual differences and metacognitive knowledge of visual search strategy. PLoS ONE, 6(10), e27043. doi:10. 1371/journal.pone. 0027043

Retell, J. D., Becker, S. I., \& Remington, R. W. (2015). An effective attentional set for a specific colour does not prevent capture by infrequently presented motion distractors. The Quarterly Journal of Experimental Psychology, 1-26. doi: 10.1080/17470218.2015. 1080738
Roberti, J. W. (2004). A review of behavioral and biological correlates of sensation seeking. Journal of Research in Personality, 38, 256-279. doi:10.1016/S0092-6566(03)00067-9

Roper, Z. J., \& Vecera, S. P. (2012). Searching for two things at once: Establishment of multiple attentional control settings on a trial-bytrial basis. Psychonomic Bulletin \& Review, 19, 1114-1121. doi:10. 3758/s13423-012-0297-8

Russo, J. E., \& Dosher, B. A. (1983). Strategies for multiattribute binary choice. Journal of Experimental Psychology: Learning, Memory, and Cognition, 9, 676-696. doi:10.1037/0278-7393.9.4.676

Sarter, M., \& Paolone, G. (2011). Deficits in attentional control: Cholinergic mechanisms and circuitry-based treatment approaches. Behavioral Neuroscience, 125, 825-835. doi:10.1037/a0026227

Scolari, M., \& Serences, J. T. (2009). Adaptive allocation of attentional gain. The Journal of Neuroscience, 29, 11933-11942. doi:10.1523/ JNEUROSCI.5642-08.2009

Shen, J., Reingold, E. M., \& Pomplun, M. (2000). Distractor ratio influences patterns of eye movements during visual search. Perception, 29, 241-250. doi: $10.1068 / \mathrm{p} 2933$

Simon, H. A. (1959). Theories of decision-making in economics and behavioral science. The American Economic Review, 49, 253-283.

Smallman, H. S., \& Boynton, R. M. (1990). Segregation of basic colors in an information display. Journal of the Optical Society of America A, 7, 1985-1994. doi:10.1364/JOSAA.7.001985

Smith, S. L. (1962). Color coding and visual search. Journal of Experimental Psychology, 64, 434-440. doi:10.1037/h0047634

Sobel, K. V., \& Cave, K. R. (2002). Roles of salience and strategy in conjunction search. Journal of Experimental Psychology: Human Perception and Performance, 28, 1055-1070. doi:10.1037//00961523.28.5.1055

Sperling, G. (1960). The information available in brief visual presentations. Psychological Monographs: General and Applied, 74, 1-29. doi:10.1037/h0093759

Treisman, A. (1988). Features and objects: The 14th Bartlett Memorial Lecture. The Quarterly Journal of Experimental Psychology, 40, 201-237. doi:10.1080/02724988843000104

Treisman, A. M., \& Gelade, G. (1980). A feature-integration theory of attention. Cognitive Psychology, 12, 97-136. doi:10.1016/00100285(80)90005-5

Treisman, A., \& Sato, S. (1990). Conjunction search revisited. Journal of Experimental Psychology: Human Perception and Performance, 16, 459-478. doi:10.1037/0096-1523.16.3.459

Vatterott, D. B., \& Vecera, S. P. (2012). Experience-dependent attentional tuning of distractor rejection. Psychonomic Bulletin \& Review, 19, 871-878. doi:10.3758/s13423-012-0280-4

Vickery, T. J., King, L. W., \& Jiang, Y. (2005). Setting up the target template in visual search. Journal of Vision, 5, 81-92. doi:10.1167/5.1.8

von Neumann, J., \& Morgenstern, O. (1953). Theory of Games and Economic Behavior (3rd ed.). Princeton: Princeton University Press.

Von Wright, J. M. (1970). On selection in visual immediate memory. Acta Psychologica, 33, 280-292. doi:10.1016/0001-6918(70)90140-X

Walton, M. E., Bannerman, D. M., Alterescu, K., \& Rushworth, M. F. (2003). Functional specialization within medial frontal cortex of the anterior cingulate for evaluating effort-related decisions. The Journal of Neuroscience, 23, 6475-6479.

Wolfe, J. M. (1994). Guided search 2.0: A revised model of visual search. Psychonomic Bulletin \& Review, 1, 202-238. doi:10.3758/ BF03200774

Wolfe, J. M. (2007). Guided search 4.0: Current progress with a model of visual search. In W. Gray (Ed.), Integrated models of cognitive systems (pp. 99-119). New York: Oxford.

Wolfe, J. M. (2013). When is it time to move to the next raspberry bush? Foraging rules in human visual search. Journal of Vision, 13(3):10. doi:10.1167/13.3.10

Wolfe, J. M., Cave, K. R., \& Franzel, S. L. (1989). Guided search: An alternative to the feature integration model for visual search. Journal 
of Experimental Psychology: Human Perception and Performance, 15, 419-433. doi:10.1037/0096-1523.15.3.419

Wolfe, J. M., \& Horowitz, T. S. (2004). What attributes guide the deployment of visual attention and how do they do it? Nature Reviews Neuroscience, 5, 1-7. doi:10.1038/nrn1411

Wolfe, J. M., Yu, K. P., Stewart, M. I., Shorter, A. D., Friedman-Hill, S. R., \& Cave, K. R. (1990). Limitations on the parallel guidance of visual search: Color $\mathrm{x}$ color and orientation $\mathrm{x}$ orientation conjunctions. Journal of Experimental Psychology: Human Perception and Performance, 16, 879-892. doi:10.1037/0096-1523.16.4.879

Woodman, G. F., \& Luck, S. J. (2004). Visual search is slowed when visuospatial working memory is occupied. Psychonomic Bulletin \& Review, 11, 269-274. doi:10.3758/BF03196569

Wyble, B., Bowman, H., \& Potter, M. C. (2009). Categorically defined targets trigger spatiotemporal visual attention. Journal of Experimental Psychology: Human Perception and Performance, 35, 324-337. doi:10.1037/a0013903

Wyble, B., Folk, C., \& Potter, M. C. (2013). Contingent attentional capture by conceptually relevant images. Journal of Experimental
Psychology: Human Perception and Performance, 39, 861-871. doi:10.1037/a0030517

Yantis, S. (1998). Control of visual attention. In H. Pashler (Ed.), Attention (pp. 223-256). East Sussex: Psychology Press.

Yantis, S., \& Jonides, J. (1984). Abrupt visual onsets and selective attention: evidence from visual search. Journal of Expimental Psychology: Human Percepttion and Performance, 10, 601-621. doi:10.1037/0096-1523.10.5.601

Yantis, S., \& Jonides, J. (1990). Abrupt visual onsets and selective attention: Voluntary versus automatic allocation. Journal of Experimental Psychology: Human Perception and Performance, 16, 121-134. doi:10.1037/0096-1523.16.1.121

Yoshida, W., \& Ishii, S. (2006). Resolution of uncertainty in prefrontal cortex. Neuron, 50, 781-789. doi:10.1016/j.neuron.2006.05.006

Zelinsky, G. J. (1996). Using eye saccades to assess the selectivity of search movements. Vision Research, 36, 2177-2187. doi:10.1016/ 0042-6989(95)00300-2 